\title{
Hyers-Ulam stability of some partial differential equations
}

\author{
NicOlaie LUNGU and DORIAN POPA
}

\section{ABSTRACT.}

In this paper we obtain a Hyers-Ulam stability result for a first order partial differential equation in Banach spaces. As a consequence follows stability results for an $n$ order partial differential equation.

\section{REFERENCES}

[1] Alsina, C. and Ger, R., On some inequalities and stability results related to the exponential function, J. Inequal. Appl., 2 (1998), 373-380

[2] András, S. and Mészáros, A. R., Ulam-Hyers stability of elliptic partial differential equations in Sobolev spaces, Appl. Math. Comput., 229 (2014), 131-158

[3] Brzdek, J., Popa, D. and Xu, B., The Hyers-Ulam stability of nonlinear recurrences, J. Math. Anal. Appl., 335 (2007), 443-449

[4] Cîmpean, D. S and Popa, D., Hyers-Ulam stability of Euler's equation, Appl. Math. Lett., 24 (2011), 1539-1543

[5] Gordji, M. S., Cho, I. J., Ghaemi, M. B. and Alizadeh, B., Stability of the second order partial differential equations, J. Inequal. Appl., 2011, 2011:81

[6] Hegyi, B. and Jung, S. -M., On the stability of Laplace's equation, Appl. Math. Lett., 26 (2013), 549-552

[7] Hyers, D. H., On the stability of the linear functional equation, Proc. Matl. Acad. Sci. USA, 27 (1941), 222-224

[8] Hyers, D. H., Isac, G. and Rassias, Th. M., Stability of Functional Equations in Several Variables, Birkhäuser, Basel, 1998

[9] Jung, S. -M., Hyers-Ulam-Rassias Stability of Functional Equations in Mathematical Analysis, Hadronic Press, Palm Harbour, 2001

[10] Jung, S. -M., Hyers-Ulam stability of a system of first order linear differential equations with constant coefficients, J. Math. Anal. Appl., 320 (2006), 549-561

[11] Jung, S. -M. and Lee, K. -S., Hyers-Ulam stability of first order linear partial differential equations with constant coefficients, Math. Inequal. Appl., 10 (2007), 261-266

[12] Jung, S. M., Hyers-Ulam stability of linear partial differential equations of first order, Appl. Math. Lett, 22 (2009), 70-74

[13] Lungu, N. and Popa, D., Hyers-Ulam stability of a first order partial differential equation, J. Math. Anal. Appl., 385 (2012), 86-91

[14] Lungu, N. and Popa, D., On the Hyers-Ulam stability of a first order partial differential equation, Carpathian J. Math., 28 (2012), 77-82

[15] Lungu, N. and Rus, I. A., Ulam stability of nonlinear hyperbolic partial differential equations, Carpathian J. Math., 24 (2008), 403-408

[16] Miura, T., Miyajima, S. and Takahasi, S. E., A characterization of Hyers-Ulam stability of first order linear differential operators, J. Math. Anal. Appl., 286 (2003), 136-146

[17] Miura, T., Miyajima, S. and Takahasi, S. E., Hyers-Ulam stability of linear differential operator with constant coefficients, Math. Nachr., 258 (2003), 90-96

[18] Popa, D., Hyers-Ulam-Rassias stability of a linear recurrence, J. Math. Anal. Appl., 309 (2005), 591-597

[19] Obloza, M., Hyers-Ulam stability of the linear differential equations, Rocznik Nauk.-Dydakt. Prace. Mat., 13 (1993), 259-270

[20] Obloza, M., Connections between Hyers and Lyapunov stability of the ordinary differential equations, Rocznik Nauk.-Dydact. Prace Mat., 14 (1997), 141-146

Received: 06.11.2013; In revised form: 17.10.2014; Accepted: 20.10.2014

2010 Mathematics Subject Classification. 39B72.

Key words and phrases. Partial differential equation, Hyers-Ulam stability.

Corresponding author: Dorian Popa; popa.dorian@math.utcluj.ro 
[21] Popa, D. and Raşa, I., On Hyers-Ulam stability of the linear differential equation, J. Math. Anal. Appl., 381 (2011), 530-537

[22] Prástaro, A. and Rassias, Th. M., Ulam stability in geometry PDE's, Nonlinear Funct. Anal. Appl., 8 (2003), No. 2, 259-278

[23] Rassias, Th. M., On the stability of the mapping in Banach spaces, Proc. Amer. Math. Soc., 72 (1978), 297-300

[24] Rus, I. A., Remarks on Ulam stability of the operatorial equations, Fixed Point Theory, 10 (2009), 305-320

[25] Takahasi, S. E., Miura, T. and Miyajima, S., On the Hyers-Ulam stability of the Banach space-valued differential equation $y^{\prime}=\lambda y$, Bull. Korean Math. Soc., 39 (2002), 309-315

[26] Takahasi, S. E., Takagi, H., Miura, T. and Miyajima, S., The Hyers-Ulam stability constants of first order linear differential operators, J. Math. Anal. Appl., 296 (2004), 403-409

[27] Ulam, S. M., A Collection of Mathematical Problems, Interscience, New York, 1960

DePARTMENT OF MATHEMATics,

TECHNICAL UNIVERSITY OF CLUJ-NAPOCA,

Memorandumului 28, 400114 Cluj-Napoca, Romania

E-mail address: nlungu@math.utcluj.ro; Popa.Dorian@math.utcluj.ro 